\title{
El desarrollo normativo posterior a la Constitución Apostólica Pastor Bonus de los tribunales de la Curia Romana
}

\section{Normative Development of the Courts of the Roman Curia Following the Apostolic Constitution Pastor Bonus}

\section{Eduardo BAURA}

Profesor Ordinario de Derecho Canónico

Pontificia Università della Santa Croce. Facoltà di Diritto Canonico. Roma

ebaura@pusc.it

Resumen: Aparte de la Penitenciaría Apostólica, competente para el fuero interno, la Constitución Apostólica Pastor Bonus señala como tribunales la Signatura Apostólica y la Rota Romana. A estos dos habría que añadir el Supremo Tribunal de la Congregación para la Doctrina de la Fe. Sin detenerse en el examen de otros dicasterios que ejercen algunas competencias de carácter judicial, el artículo estudia los actos pontificios emanados después de la Pastor Bonus, que han ido configurando la composición y las funciones de estos tres tribunales. A raíz de los datos estudiados, se proponen algunas consideraciones acerca de la ausencia de algunas exigencias formales en la emanación de los actos examinados y sobre la tendencia a seguir la vía administrativa para la imposición de penas. Por último, se sugieren algunas reflexiones acerca del papel de la jurisprudencia, remarcando la distinción entre la doctrina jurisprudencial y la doctrinal e intentando delimitar la función de la Rota en este ámbito.

Palabras clave: Tribunales, Curia Romana, Jurisprudencia.
Abstract: Apart from the Apostolic Penitentiary, whose area of competence covers the internal forum, the Apostolic Constitution Pastor Bonus designates the Apostolic Signature and the Roman Rota as tribunals of the Roman Curia. The Supreme Tribunal of the Congregation for the Doctrine of the Faith could also be included on this list. Without addressing other dicasteries that exercise some jurisdictions of a legal nature, this article studies the pontifical acts following Pastor Bonus, which have shaped the structure and functions of these three courts. A study of the available information prompts some consideration of the lack of formal requirements in the issuance of the acts under examination, and a tendency to follow administrative procedures in imposing penalties. Finally, a number of reflections on the role of jurisprudence are set out, highlighting the distinction between jurisprudential doctrine and general teaching, so as to better define the role of the Roman Rota in this regard.

Keywords: Tribunals, Roman Curia, Jurisprudence. 
P ara afrontar el tema de las competencias de los tribunales de la Curia Romana hay que definir en primer lugar cuáles son estos tribunales, asunto que puede parecer baladí, pero que requiere en realidad una atenta consideración. La Constitución Apostólica Pastor Bonus ${ }^{1}$ (en adelante PB), bajo la rúbrica tribunalia trata de la Penitenciaría Apostólica, del Supremo Tribunal de la Signatura Apostólica y del Tribunal de la Rota Romana. En este trabajo no tomaré en consideración la Penitenciaría Apostólica porque no se trata de un tribunal que juzgue los derechos de causas contenciosas, sino que su función judicial se mueve en el ámbito del llamado fuero interno. En cambio, estudiaré el Supremo Tribunal de la Congregación para la Doctrina de la $\mathrm{Fe}$, que, como es sabido, tiene una gran importancia en el ámbito penal y ha sido objeto de un notable desarrollo normativo posterior a la PB. No me entretengo, en cambio, en algunas competencias de otros dicasterios que podrían ser consideradas de algún modo judiciales, como sería la actividad procesal en las causas de canonización o en las decisiones administrativas penales tomadas por algunos dicasterios en virtud de facultades extraordinarias.

El objetivo del presente trabajo es, luego de recordar los desarrollos normativos que han tenido lugar con posterioridad a la promulgación de la PB en relación con los tres tribunales citados, proponer algunas reflexiones que en cierta medida pueden ser consideradas como sugerencias de lege ferenda. Por tanto, se trata primero de repasar -sin ninguna pretensión de originalidad- las distintas intervenciones que la autoridad competente ha realizado sobre estos tribunales, pues, a pesar de que son de sobra conocidas, resulta útil recogerlas con orden para tomar mayor conciencia de los cambios operados y de su alcance. En un segundo momento, intentaré recoger los hilos para apuntar algunas observaciones que suscitan los desarrollos normativos habidos en esta materia.

\section{La Congregación Para la Doctrina de la Fe}

Los artículos 48 a 55 de la PB describen la Congregación para la Doctrina de la Fe (en adelante CDF), asignándole el papel principal de promover y tutelar la doctrina, lo que puede llevarse a cabo mediante actos administrativos: licencias, aprobaciones, prohibiciones, advertencias y tantas otras medi1 San Juan Pablo II, Constitución Apostólica Pastor Bonus, de 29 de junio de 1988 (AAS 80 [1988]
841-930). 
das de gobierno o actos que administran el bien público relativo a la custodia y promoción de la fe. Por lo que se refiere al desarrollo de su función principal, no hay ningún inconveniente en que este dicasterio sea calificado como Congregación y, por tanto, como uno de los organismos de la Curia Romana que ejercen la función administrativa dentro de su competencia (en este caso definido por un criterio material) con potestad vicaria.

Para ejercer la función de proteger la doctrina es necesario, entre otras acciones, "juzgar" los escritos. Se trata de realizar una operación intelectual de valoración, pero de carácter objetivo, referida a un escrito, y no a la conducta del autor. Esa valoración o "juicio" puede llevar consigo la provisión de algunas medidas en relación con el escrito e incluso respecto al autor (por ejemplo, retiro de la venia docendi), pero, en mi opinión, no hay inconveniente para que el conjunto de estas actividades se realice según un procedimiento administrativo justo, quedando encuadradas dentro de la función administrativa. Las normas emanadas para el examen de las doctrinas permiten defender la ortodoxia de la opinión sub iudice dentro de un procedimiento administrativo ${ }^{2}$.

En cambio, el juicio sobre el comportamiento de quien expresa una determinada opinión, juicio que puede llevar consigo la imposición de penas canónicas, constituye sin duda una actividad de tipo judicial. Naturalmente, para juzgar un delito contra la fe primero hay que proceder a la valoración objetiva de la doctrina en cuestión. Se comprende por esto la vis atractiva de la estimación doctrinal objetiva, que lleva a que el mismo órgano encargado de esta actividad juzgue las conductas delictivas sobre la misma materia, aunque, en mi opinión, es posible separar ambas actividades, y, desde el punto de vista de la tutela de los derechos de los fieles, resulta deseable.

Pero esta fuerza atractiva ha ido más lejos, ya desde su inicio histórico, haciendo que esta Congregación se ocupase también de juzgar conductas, no tanto contrarias a la fe, sino sencillamente contra la moral, quizás porque eran consideradas reflejo de una actitud contraria a la fe, como es el caso de aquellas que delatan falsas conversiones o deficiencia en la creencia en los sacramentos u otras desviaciones doctrinales ${ }^{3}$.

${ }^{2}$ Cfr. CDF, Agendi ratio pro doctrinarum examine, de 29 de junio de 1997 (AAS 89 [1997] 830-835).

${ }^{3}$ Puede verse una historia de la Congregación, realizada por ella misma, en la página web oficial de este dicasterio (www.vatican.va) en la sección Storia e organizzazione. Cfr. también N. DEL RE, La Curia Romana. Lineamenti storico-giuridici, Libreria Editrice Vaticana, Città del Vaticano 1998, 95-101. 
La tendencia a concentrar en el mismo organismo la función de valorar la ortodoxia y la competencia sobre el juicio de las conductas delictivas que pueden tener relación con la doctrina ha llevado a asignar a este mismo organismo la tarea de juzgar también los delitos más graves contra la moral, aun cuando no estuviesen relacionados con la doctrina. La Constitución Apostólica Regimini Ecclesiae Universae hacía referencia a la competencia de la CDF sobre la tutela de las buenas costumbres (art. 29) y de la dignidad del sacramento de la Penitencia (art. 36), en términos que daban por supuesto su competencia judicial, si bien no determinaba cuáles eran los delitos sobre los que podía juzgar ${ }^{4}$. Siguiendo esta tendencia, el art. 52 de la $\mathrm{PB}$ dispone que este dicasterio «delicta contra fidem necnon graviora delicta tum contra mores tum in sacramentorum celebratione commissa, quae ipsi delata fuerint, cognoscit atque, ubi opus fuerit, ad canonicas sanctiones declarandas aut irrogandas ad normam iuris, sive communis sive proprii, procedit».

Durante los primeros años de vigencia de la $\mathrm{PB}$ quedaba indeterminada la competencia judicial de la Congregación ${ }^{5}$. El Código promulgado en 1983 había abrogado todas las leyes penales emanadas por la Santa Sede que no estuviesen recogidas en el mismo Código (can. $6, \$ 1,3^{\circ}$ ) y en materia penal había establecido algunas reservas a favor de la Santa Sede, sin especificar cuál era el dicasterio competente, si bien presuponía que la CDF tendría competencia judicial en este ámbito, pues, al tratar de la prescripción de la acción criminal, excluía los delitos reservados a esta Congregación (can. 1362, $\$ 1,1^{\circ}$ ).

Hasta 1983 existía una norma no promulgada, producida en 1962 (que consiste sustancialmente en una reedición de una precedente Instrucción, tampoco promulgada, de 1922) ${ }^{6}$, que tipificaba y establecía el proceso de punición ante la CDF del crimen sollicitationis y del crimen pessimum, o sea, el delito de homosexualidad perpetrado por un clérigo, al que se equiparaba el delito «cum impuberibus cuiusque sexus vel cum brutis animantibus». Con la entrada en vigor del Código -que, como se ha dicho, abrogaba las leyes penales emanadas

${ }^{4}$ Cfr. Pablo VI, Constitución Apostólica Regimini Ecclesiae Universae, de 15 de agosto de 1967, AAS 59 (1967) 885-928.

5 Cfr. J. Llobell, Sulla promulgazione delle norme processuali proprie della Congregazione per la dottrina della fede in materia penale, Ius Ecclesiae 9 (1997) 289-301.

${ }^{6}$ Cfr. Suprema Sacra Congregatio Sancti Officil, Instructio de modo procedendi in causis sollicitationis, de 9 de junio de 1922 y de 16 de marzo de 1962, difundidas en internet (la primera se puede consultar en http://www.bishop-accountability.org/archives/Wall/1922_06_09_Solicitation_Instruction_Latin.pdf [consultado el 25 de octubre de 2017] y la segunda, por ejemplo, en http://www.cesnur.org/2007/Crimen_1962.pdf [visitado el 25 de octubre de 2017]). 
por la Santa Sede no recogidas en el mismo Código (can. $6, \$ 1,3^{\circ}$ )- se ha pensado que la Instrucción de 1962 permaneciese en vigor (en la medida en que puede estar vigente de hecho una norma general no promulgada) en lo que se refiere a la parte procesal respecto al delito de solicitación, que había sido recogido en el can. 1387, y acerca del delito contra sextum, ya que quedaba tipificado en el can. $1395^{7}$. En virtud de esta Instrucción la CDF sería competente para conocer las apelaciones contra la pena impuesta por estos delitos, amén de la posibilidad de juzgar en primera instancia por encargo o avocación.

Así las cosas, en 1994, como consecuencia de los graves y numerosos escándalos que surgieron, se dieron unas normas especiales para los Estados Unidos mediante un rescripto ex audientia Ss.mi, concernientes al delito de pederastia, en las que se afirmaba expresamente que no quedaba derogado el can. $1444, \$ 1,1$, relativo a la competencia de la Rota como tribunal de apelación $^{8}$. Ahora bien, esa referencia a la Rota parecía excluir la competencia de la CDF y la vigencia (de hecho) de la Instrucción de $1962^{\circ}$.

La incertidumbre se superó mediante la promulgación del Motu Proprio de san Juan Pablo II, Sacramentorum sanctitatis tutela, de 30 de abril de $2001{ }^{10}$. El Motu Proprio se remitía a normas sustanciales y procesales que no han sido nunca oficialmente promulgadas, pero que actualmente son accesibles fácilmente $^{11}$. El art. 8 de estas normas se refería a la CDF como el Supremo Tribunal apostólico para la Iglesia latina y para las Iglesias orientales católicas en materia de delicta graviora. Las normas indicaban cuáles eran estos delitos reservados a la CDF (cuatro referentes al sacramento de la Eucaristía, tres rela-

${ }^{7}$ Cfr. D. CiTo, Congregazione per la Dottrina della Fede. Normae «de gravioribus delictis», en M. DEL PozZo - J. Llobell - J. MiÑAmbres, Norme procedurali canoniche commentate, Coletti a San Pietro, Roma 2013, 629.

8 San Giovanni Paolo II, Rescripto ex audientia Ss.mi, de 25 de abril de 1994, firmado por el Secretario de Estado. Puede consultarse en Ius Ecclesiae 8 (1996) 193. Las normas contenidas en este rescripto fueron extendidas para Irlanda en 1996 (cfr. CONGREGACIÓN PARA LA DOCTRINA $\mathrm{DE} \mathrm{LA} \mathrm{FE}$, Le norme del motu proprio «Sacramentorum sanctitatis tutela». Introduzione storica, en http://www.vatican.va/resources/resources_introd-storica_it.html [visitado el 25 de octubre de 2017]).

9 Cfr. J. Llobell, Sulla promulgazione..., cit., 297-298.

${ }^{10}$ AAS 93 (2001) 737-739.

${ }^{11}$ Por ejemplo, en Ius Ecclesiae 16 (2004) 313-320. El Motu Proprio concluía afirmando que «ipsae Normae vim legis exserunt eadem die qua promulgatae sunt». Aparte de los problemas que plantea una inmediata vigencia de una norma penal y procesal sin ningún tipo de vacatio legis, esas normas no han sido nunca "promulgadas" a tenor del can. 8. Fue, en cambio, publicada una carta de la CDF, de 18 de mayo de 2001, a los Obispos y demás Ordinarios y Jerarcas interesados en la que se ilustraban las nuevas normas (AAS 93 [2001] 785-788). 
tivos a la santidad del sacramento de la Penitencia y el delito contra el sexto mandamiento cometido por un clérigo con un menor). Prescribían la obligación del Ordinario de informar a la CDF de la notitia criminis, a la cual competía indicar al Ordinario cómo proceder, dejando a salvo el derecho de avocación del dicasterio (en primera instancia) y su competencia exclusiva (tanto respecto a los tribunales locales como a la Rota Romana) como tribunal de apelación, quedando excluida la vía administrativa ${ }^{12}$. El término de prescripción de la acción criminal era fijado por estas normas en diez años, bien entendido que en el caso del delito de pederastia el cómputo debía empezar a partir de que la víctima cumpliese los dieciocho años de edad.

Después del Sacramentorum sanctitatis tutela la CDF pidió al Romano Pontífice algunas facultades especiales que facilitasen su función de juzgar los delitos más graves. Así, el 7 de noviembre de 2002, el Papa otorgó a la CDF la facultad de «derogar los términos de la prescripción» de la acción criminal en casos singulares. El 7 de febrero de 2003 fueron introducidas por el Papa otras modificaciones: la tipificación de dos delitos más considerados graviora (la violación indirecta del sigilo sacramental y la grabación, verdadera o falsa, de las confesiones o su divulgación) y la concesión de dos facultades extraordinarias a la CDF (la facultad de dispensar de algunos requisitos a los jueces encargados de un delito reservado y la de seguir la vía administrativa para la imposición de la pena de la dimisión del estado clerical o trasladar la causa directamente al Santo Padre para la dimisión ex officio). En la audiencia del 14 de febrero de 2003, el Romano Pontífice estableció que todos los recursos contra los decretos administrativos penales emanados por la CDF fuesen deferidos a la Feria IV de la misma Congregación, es decir, que fuesen excluidos del contencioso administrativo ante la Signatura Apostólica ${ }^{13}$. Estas facultades fueron confirmadas por Benedicto XVI el 6 de mayo de $2005^{14}$.

Las modificaciones introducidas después del Motu Proprio Sacramentorum sanctitatis tutela han sido recogidas en las vigentes Normae de delictis Con-

12 «Delicta graviora Congregationi pro Doctrina Fidei reservata, nonnisi in processu iudiciali persequenda sunt» (art. 17 del Motu Proprio Sacramentorum sanctitatis tutela).

13 Todos estos actos (del 7 de noviembre de 2002, del 7 de febrero de 2003 y del 14 de febrero de 2003) pueden consultarse, entre otros lugares en Ius Ecclesiae 16 (2004) 320 y 321, y en W. WOESTMAN, Ecclesiastical sanctions and the penal process. A commentary on the Code of Canon Law, Otawa 22003, 314-316.

${ }^{14}$ Cfr. CDF, Breve relación sobre los cambios introducidos en las Normae de gravioribus delictis reservados a la Congregación para la Doctrina de la Fe, en www.vatican.va. 
gregationi pro Doctrina Fidei reservatis seu Normae de delictis contra fidem necnon de gravioribus delictis, aprobadas mediante un rescripto «ex audientia Sanctissi$m i »$, de 21 de mayo de $2010^{15}$, que fueron formalmente promulgadas junto con una Carta de la CDF a los obispos y una Relazione sobre las principales novedades respecto a las Normas de $2001{ }^{16}$.

La normativa vigente, por tanto, reserva una serie de delitos al juicio de la CDF, la cual, a tenor del art. 21, $\$ 2$ de las Normas de 2010 (y contrariamente a lo previamente establecido por el art. 17 del Motu Proprio Sacramentorum sanctitatis tutela), puede juzgarlos por vía judicial o administrativa ${ }^{17}$. En ambos casos puede servirse de los jueces que lo son ipso iure por ser miembros de la Congregación o de otros nombrados ad casum (arts. 9 y 10 de las Normas de 2010). El Supremo Tribunal de la CDF juzga en segunda instan-

15 AAS 102 (2010) 419-430.

${ }^{16}$ Cfr. ibid., 431-434. De todos modos, la nueva normativa se divulgó antes de su promulgación, lo que suscitó algunas dudas acerca de la fecha exacta de su efectiva emanación; cfr. S. LOPPACHER, Processo penale canonico e abuso sessuale su minori. Un'analisi dei recenti sviluppi normativi intorno al «delictum contra sextum cum minore» alla luce degli elementi essenziali di un giusto processo, Pontificia Università della Santa Croce, Roma 2017, 69-71. En esta misma obra se puede consultar el itinerario de las normas y decisiones que han llevado a la situación vigente en materia de competencia penal de la CDF desde la promulgación del Código con las oportunas refencias a los documentos y a la bibliografía científica que los comenta (cfr. ibid., 22-68). Sobre las modificaciones introducidas en 2010, en comparación con la normativa emanada en el 2001, cfr. D. CiTO, Las nuevas normas sobre los «delicta graviora», Ius Canonicum 50 (2010) 643-658; T. J. GREEN, Sacramentorum sanctitatis tutela. Reflections on the Revised May 2010 Norms on More Serious Delicts, The Jurist 71 (2011) 120-158 y los trabajos contenidos en la obra colectiva de A. D'AurIA C. PAPAle (eds.), I delitti riservati alla Congregazione per la Dottrina della Fede, Urbaniana University Press, Città del Vaticano 2014.

17 En cuanto a la reserva conviene advertir que no se ha de confundir con la mera reserva de la remisión de la pena, ya que la reserva del delito comprende también la irrogación o declaración de la pena (cfr., por ejemplo, V. DE PAOLIS, Norme de gravioribus delictis riservati alla Congregazione per la dottrina della fede, Periodica 91 [2002] 299). Se ha hecho notar que la reserva de los delitos a la CDF está unida al instituto de la avocación, de manera que, precisamente porque se trata de avocación, se presupone que subsiste la competencia de otro tribunal. En otras palabras, no hay que confundir la reserva con la competencia exclusiva: en primera instancia subsistiría la competencia del tribunal local, de suerte que si la CDF decidiese dar la orden de proceder al tribunal inferior, tal decisión no consistiría en rigor en una prórroga de jurisdicción (cfr. J. LLOBell, Processi e procedure penali: sviluppi recenti, en H. FranCESCHI - M. A. OrTIZ [eds.], «Ius et matrimonium». Temi di diritto matrimoniale e processuale canonico. $V$ Corso di aggiornamento in diritto matrimoniale e processuale canonico. Roma, 16-20 settembre 2013, Edusc, Roma 2015, 88, y S. Loppacher, Processo penale canonico..., cit., 191-195). En la práctica, resulta relevante la intervención de las autoridades inferiores (en la gestión de la notitia criminis y, en la mayoría de los casos, en la fase de instrucción). En el caso de que un tribunal inferior juzgase sin la orden de la CDF de proceder, actuaría como un tribunal con incompetencia relativa, con la consecuencia establecida en el can. $1460, \$ 2$. La competencia de la CDF es exclusiva, en cambio, respecto a otros tribunales de la Curia Romana, y en segunda instancia lo es en términos absolutos. 
cia las causas definidas en primera instancia por los tribunales inferiores y por el mismo Supremo Tribunal (art. 20). En el caso de que la causa haya sido decidida por decreto administrativo de la CDF, cabe solamente recurso contra la Feria IV de la CDF, que juzga sobre el mérito y la legitimidad del decreto impugnado, quedando excluido de esta manera el contencioso administrativo ante la Signatura Apostólica.

La doctrina ha llamado la atención sobre algunos puntos débiles de este sistema (la vía administrativa para imponer penas, la inseguridad jurídica en materia de prescripción penal y otros de este tipo), entre los que se encuentra la deficiencia del segundo grado de jurisdicción. «Por razón del número de recursos», pero quizá para salir al paso de la falta de una verdadera segunda instancia, ha sido creado en el seno de la CDF, mediante un rescripto ex audientia Ss.mi, un Colegio formado por siete cardenales y obispos, que pueden ser o no miembros de la $\mathrm{CDF}^{18}$. En el rescripto se afirma que este Colegio es una instancia de la que la Sesión Ordinaria (Feria IV) de la Congregación se dota para una mayor eficiencia en el examen de los recursos, pero se añade, sin que se modifiquen las competencias de la misma CDF. Parece, pues, que en el texto de este Rescripto subyacen dos tendencias: una que intenta constituir una nueva instancia y otra que quiere proteger las competencias de la CDF. El Reglamento emanado por el Secretario de Estado, de mandato Summi Pontificis, el 12 de mayo de 2015 ha confirmado la segunda línea, de manera que queda sin resolver el problema de una verdadera segunda instancia en materia de los procesos penales ante la $\mathrm{CDF}^{19}$.

\section{El Supremo Tribunal de la Signatura Apostólica}

La descripción que del Supremo Tribunal de la Signatura Apostólica hace la PB (arts. 121 a 125) recoge lo establecido en el can. 1445, acerca de la competencia judicial de este tribunal, y con la configuración que la Regimini Ecclesiae Universae había dado a este dicasterio (arts. 104 a 108).

${ }^{18}$ FrancisCo, Rescripto ex audientia Ss.mi, De Collegio intra Congregationem pro Doctrina Fidei constituendo ad appellationes clericorum circa graviora delicta considerandas, 3 de noviembre de 2014, AAS 106 (2014) 885-886. Al final del texto del Rescripto se afirma que «il Santo Padre ha disposto che il presente decreto generale esecutivo sia promulgato...». Resulta claro por el contenido y por la forma del acto en cuestión que la calificación de decreto general ejecutivo es un error, pues este Rescripto no posee en absoluto las características del tipo de norma contemplado en el can. $31, \$ 1$.

19 Para el texto del Reglamento, con un comentario, vid. D. G. AstigueTA, Il nuovo Collegio all'interno della Congregazione per la dottrina della fede e il suo regolamento, Periodica 105 (2016) 335-363. 
La Constitución Apostólica de 1967 hablaba de dos Secciones de la Signatura. La primera se debía encargar de las competencias judiciales que le reconocían los cann. 1603 a 1605 del Código entonces vigente, correspondientes en líneas generales al actual can. 1445, en cuya virtud la Signatura juzga las querellas de nulidad, las peticiones de restitutio in integrum y los recursos rechazados por la Rota Romana de nova causae propositio y otros recursos contra las sentencias rotales, así como las exceptiones suspicionis y otras causas contra los auditores de la Rota Romana; juzga también los conflictos de competencia entre tribunales no sujetos al mismo tribunal de apelación. Esta primera Sección se ocupa además de los aspectos de gobierno referentes a la vigilancia de la administración de justicia. La Regimini Ecclesiae Universae introdujo la novedad de crear una segunda Sección dentro de este dicasterio, con la competencia de ocuparse de juzgar el contencioso administrativo, o sea, de juzgar la legitimidad de los actos administrativos singulares emanados por los dicasterios de la Curia Romana. Como se ve, las dos Secciones cubrían en realidad tres ámbitos: el de gobierno administrativo, característico de un ministerio de justicia, el de tribunal supremo respecto a determinadas causas y el de tribunal administrativo. La PB no habla de secciones, pero mantiene la asignación a la Signatura Apostólica de las tres funciones mencionadas.

$\mathrm{Al}$ igual que la Constitución Apostólica precedente, la PB (art. 125) concluye afirmando que «Signatura Apostolica lege propria regitur». Después de la Regimini Ecclesiae Universae, con fecha de 25 de marzo de 1968 fueron dadas las Normae speciales in Supremo Tribunali Signaturae Apostolicae ad experimentum servandae post Constitutionem Apostolicam Pauli pp. VI, que no llegaron nunca a promulgarse formalmente, aunque se divulgaron en distintas publicaciones. A pesar de que las normas eran ad experimentum y de que no fueron nunca promulgadas, de hecho han sido aplicadas durante cuarenta años (con algunas pequeñas reformas ${ }^{20}$ ), desde 1968 hasta la emanación de la vigente Lex propria de la Signatura por Benedicto XVI, mediante el Motu Proprio Antiqua ordinatione, de 21 de junio de 2008, que fue oficialmente promulgado, si bien el retraso de la publicación del correspondiente fascículo de AAS hizo que sur-

${ }^{20}$ Por ejemplo, la modificación del art. $1, \$ 1$, relativo a la misma composición de la Signatura (cfr. Secretaría De Estado, Carta del 14 de marzo de 1977, Prot. N. 305831, en Z. GrochoLEWSKI, La «Sectio Altera» della Segnatura Apostolica con particolare riferimento alla procedura in essa seguita, Apollinaris 54 [1981] 78, en nota). 
giesen dudas acerca de la fecha de su entrada en vigor ${ }^{21}$. En todo caso, el cuadro normativo vigente sobre la Signatura Apostólica está constituido por el can. 1445 del Código, los arts. 121 a 125 de la PB y por la mencionada Lex propria de 2008. El desarrollo del Supremo Tribunal de la Signatura Apostólica hay que buscarlo, por tanto, en la Lex propria de 2008.

No se trata en este trabajo de examinar con detalle dicha ley ${ }^{22}$. Basta señalar que la configuración general de la Signatura Apostólica permanece la misma, o sea, como dicasterio encargado del sector de la función administrativa de vigilar y coordinar la administración de la justicia y como tribunal con competencia sobre algunas causas contra la Rota Romana y para juzgar el contencioso administrativo. La nueva ley, en efecto, tiende a confirmar el statu quo, la estructura básica de las Normas de 1968 y la praxis de estos años. Con todo, conviene subrayar algunas novedades.

Sobre la base de la composición inmutada de la Signatura, consistente en un grupo de cardenales y obispos nombrados por el Sumo Pontífice, el art. 1, $\$ 2$ de la Lex propria añade que al conjunto de Miembros se pueden agregar algunos clérigos, de íntegra fama, doctores en derecho, que se distingan por la doctrina canónica. El añadido es importante y refleja la voluntad de dotar el Supremo Tribunal de profesionalidad, superando, si la hubiese, una mentalidad estamental, que impediría que un presbítero o diácono pudiese juzgar un acto emanado por una Congregación presidida por un cardenal, pues entiende que la potestad de todos los jueces de la Signatura es igualmente vicaria del Papa, sin diferencias debidas a sus distintos grados de orden sagrado. Hasta la fecha esta nueva posibilidad no se ha aplicado.

La nueva ley ha reforzado la figura del Prefecto, otorgándole un poder decisorio notable en algunas provisiones relativas a la vigilancia de la administración de la justicia y otras que puede tomar durante el proceso contencioso ad-

${ }^{21}$ El Motu Proprio fue promulgado en AAS 100 (2008) 513-538. El volumen de los Acta llevaba la fecha de 1 de agosto de 2008, por lo que la ley debería entrar en vigor el 1 de noviembre del mismo año, pero el fascículo en cuestión fue distribuido más tarde. Sobre ésta y otras anomalías en la promulgación de las leyes, cfr. R. Rodríguez CHACón, Promulgación, publicación y entrada en vigor de las leyes en la Iglesia, en J. L. SÁnCHEZ-GIRÓN - C. PeÑa GARCía (eds.), El Código de Derecho Canónico de 1983. Balance y perspectivas a los 30 años de su promulgación, Universidad Pontificia Comillas, Madrid 2014, 71-105.

${ }^{22}$ Para un comentario a la Lex propria, cfr. R. BuRKE, Presentazione, en Norme procedurali canoniche commentate, cit., 29-34; F. DANEELs, La nuova Lex propria del Supremo Tribunale della Segnatura Apostolica, Communicationes 40 (2008) 336-341. Para un estudio más detallado de cada una de las partes de la ley, cfr. P. A. Bonnet - C. Gullo (eds.), La lex propria del S.T. della Segnatura Apostolica, Libreria Editrice Vaticana, Città del Vaticano 2010. 
ministrativo ${ }^{23}$. Para entender la relevancia de la posición jurídica del Prefecto hay que considerar la existencia y las competencias del Congreso de la Signatu$\mathrm{ra}^{24}$. A tenor del art. 22, $\$ 1$ de la Lex propria, el Congreso está compuesto por el Prefecto, Secretario, Promotor de Justicia, Defensor del vínculo, Promotores de Justicia sustitutos o deputati ad casum; al Congreso pueden ser invitados los Referendarios que se considere oportuno. Al Congreso competen numerosas funciones, pero es en el proceso contencioso administrativo donde su papel es decisivo. En este proceso es competente para juzgar el recurso contra la decisión del Secretario de rechazar a limine una demanda (art. 76, $\$ \$ 3$ y 4) o de no admitir la suspensión del acto impugnado (arts. 96, $\$ 3$ y 99), para aprobar la solución pacífica alcanzada por las partes (art. 78, $\$ 2$ ), para dirimir las controversias sobre la ejecución de la sentencia (art. 94) y sobre el conflicto de competencias entre los dicasterios (art. 105), y, a tenor del art. 83 de la Lex propria, es competente -esta es la prerrogativa más relevante- para dar un juicio preliminar sobre la admisibilidad del recurso contencioso administrativo, que va más allá de una mera valoración de la existencia del fumus boni iuris (la cual es realizada por el Secretario a limine). Se trata en la práctica de un "mini-proceso" que -además de plantear el problema de la prolongación del proceso- decide su suerte, sobre todo, cuando el recurso es rechazado, ya que, si bien es posible recurrir al Colegio de Jueces contra tal decisión (art. 84), de hecho el Colegio tiende a confirmar la decisión del Congreso ${ }^{25}$. Pues bien, el Congreso no es un órgano colegial, sino que la decisión la toma sólo el Prefecto, que es el único juez de ese organismo, de manera que los otros miembros tienen una posición meramente consultiva, aunque de hecho pueda ser muy relevante.

A propósito del juicio sobre el contencioso administrativo, hay que decir que desde la Regimini Ecclesiae Universae (art. 106), ha quedado establecido que la Signatura sólo juzga de la posible violatio legis por parte del acto adminis-

${ }^{23}$ Cfr. R. Burke, La Segnatura Apostolica: gli organi individuali, en La lex propria del S.T. della Segnatura Apostolica, cit., 79-81.

24 Sobre este organismo, cfr. J. CANOSA, Gli organi collegiali previsti dalla «Lex propria» della Segnatura Apostolica, ibid., 107-116.

25 Sobre el papel del Congreso en el contencioso administrativo, cfr. E. BAURA, Analisi del sistema canonico di giustizia amministrativa, en E. BAURA - J. CANOSA (eds.), La giustizia nell'attività amministrativa della Chiesa Il contenzioso amministrativo, Giuffrè, Milano 2006, 41-42. Acerca del proceso contencioso administrativo a la luz de la Lex propria puede verse J. MiRAS - J. CANOSA E. Baura, Compendio de derecho administrativo canónico, Eunsa, Pamplona 32017 , 307-335, y G. P. MONTINI, I ricorsi amministrativi presso il Supremo Tribunale della Segnatura Apostolica, en GRUPPO Italiano Docenti Di DiritTo Canonico (ed.), Il diritto nel mistero della Chiesa, vol. IV: Prassi amministrativa e procedure speciali, Lateran University Press, Città del Vaticano 2014, 135-159. 
trativo singular impugnado. $\mathrm{El}$ art. $123, \S 1$ de la $\mathrm{PB}$ establece asimismo que la Signatura juzga «quoties contendatur num actus impugnatus legem aliquam in decernendo vel in procedendo violaverit». Se comprende que se quiera excluir del juicio de legitimidad realizado por las autoridades judiciales la valoración sobre la oportunidad de gobierno del acto administrativo, asunto que compete a la autoridad administrativa, pero el juicio sobre la mera violación legal puede quedar de hecho demasiado restringido para que se realice verdaderamente justicia ante la actuación ilegítima de una autoridad administrativa, y así lo ha puesto de relieve la doctrina ${ }^{26}$. Ya la misma PB había extendido la competencia de la Signatura al juicio sobre la reparación de los daños causados por el acto ilegítimo (art. 123, \$2). La Lex propria, por su parte, refuerza la posibilidad de la Signatura de hacer realmente justicia sin quedarse en un mero juicio de legitimidad formal. Además de dar disposiciones concretas relativas a la reparación del daño (arts. 101 a 103), la nueva norma regula el poder del Tribunal en materia de suspensión del acto impugnado (arts. 95 a 100) y, sobre todo, otorga algunos poderes al Tribunal para garantizar la efectiva ejecución de la sentencia, tema que en la práctica ha presentado dificultades ${ }^{27}$.

En fin, un punto interesante y novedoso de la Lex propria, sobre el que volveré en sede de conclusiones, es el relativo a la publicación de la jurisprudencia. El art. 11, $\$ 4$ establece que el Canciller tiene la función de ocuparse de la recolección de todas las decisiones («ut omnes decisiones colligantur»), de las cuales algunas, elegidas todos los años por el Prefecto en el Congreso, se publican ope Supremi Tribunali.

\section{El Tribunal de la Rota Romana}

La Rota Romana es configurada en la PB (arts. 126 a 130) como Tribunal de la Sede Apostólica, que actúa ordinariamente como instancia de apelación, aunque se le asignan algunas causas en primera instancia. La PB no modifica lo dispuesto por el Código de Derecho Canónico en los cann. 1443 y 1444. La

${ }^{26}$ Cfr. E. BAURA, Analisi del sistema canonico..., cit., 43-56; J. LlObELL, Il «petitum» e la «causa petendi» nel contenzioso-amministrativo canonico. Profili sostanziali ricostruttivi alla luce della cost. ap. «Pastor Bonus», Ius Ecclesiae 3 (1991) 137-138, e I. ZUANAZZI, Praesis ut prosis. La funzione amministrativa nella diakonia della Chiesa, Casa Editrice Jovene, Napoli 2005, 417-422.

27 Cfr. G. P. Montini, L'esecuzione delle sentenze della «Sectio Altera» della Segnatura Apostolica. Il significato di una lacuna, en K. LÜDICKE - H. MussinghofF - H. SCHWENDENWEIN (eds.), Iustus Iudex. Festgabe für Paul Wesemann zum 75. Geburtstag von seinen Freunden und Schülern, Ludgerus, Essen 1990, 553-571. 
única novedad introducida por la PB no se refiere a la composición de este tribunal ni a sus competencias en sentido estricto, sino al papel que debe desempeñar respecto a la jurisprudencia. Establece el art. 126 que la Rota «provee a la unidad de la jurisprudencia y, a través de sus sentencias, sirve de ayuda a los tribunales de grado inferior». Por lo demás, el art. 130 de la $\mathrm{PB}$, al igual que el precedente art. 110 de la Regimini Ecclesiae Universae, remite a una ley propia.

Esa ley propia fue emanada en 1994 con el nombre Normae Romanae Rotae Tribunalis, fechada el 18 de abril de 1994 y firmadas por el Decano. En estas Normae se afirmaba que el Papa las había aprobado (sin declarar que lo hubiese hecho en forma específica) y que debían ser publicadas en el Acta Apostolicae Sedis, para entrar en vigor a partir del 1 de octubre de $1994^{28}$. Las Normas introducían algunas novedades respecto a la normativa entonces en vigor, por lo que se suscitaron algunas dudas acerca de su valor normativo, ya que sólo se hacía referencia a la aprobación genérica del Papa ${ }^{29}$. Por esa razón, meses después se publicó un Rescripto ex audientia Ss.mi, firmado por el Secretario de Estado y fechado el 23 de febrero de 1995, en el que se declaraba que las Normas recientemente promulgadas habían de ser entendidas como aprobadas en forma específica por el Romano Pontífice, incluso derogando a la ley universal, contrariis quibusvis non obstantibus ${ }^{30}$. De esta manera quedó confirmado inequívocamente el valor legal de las Normas.

En mi opinión, la necesidad de una intervención del Legislador supremo no era debida solamente a ciertas disposiciones que pudiesen resultar novedosas ${ }^{31}$, sino al conjunto de las Normas, ya que, además de que tratan de cuestiones procesales que pueden afectar directamente a cualquier fiel que se encuen-

${ }^{28}$ Cfr. AAS 86 (1994) 508-540.

29 Cfr. J. LlobeLL, Le norme della Rota romana in rapporto alla vigente legislazione canonica: la «matrimonializzazione» del processo; la tutela dell'«ecosistema processuale»; il principio di legalità nell'esercizio della potestà legislativa, en P. A. BONNET - C. Gullo (eds.), Le «Normae» del Tribunale della Rota romana, Libreria Editrice Vaticana, Città del Vaticano 1997, 58. Sobre el contenido de las Normae, pueden verse los otros trabajos de esta misma obra colectiva.

30 Cfr. SeCretaría de Estado, Rescriptum ex audientia Sanctissimi quo Normae Rotales in forma specifica approbantur, 23 de febrero de 1995, AAS 87 (1995) 366.

${ }^{31}$ Por ejemplo, el art. 43, $₫ 1$ habla de la obligación de los auditores de la reparación del daño («grave detrimentum») causado a las partes por dolo, después de un juicio de la Signatura Apostólica confirmado por el Romano Pontífice. El requisito de la confirmación del Romano Pontífice no estaba previsto ni en el Código ni en la PB. A mi parecer, la alusión al dolo, y no a la culpa, como única causa de la responsabilidad no permite en este caso aplicar el principio inclusio unius, exclusio alterius, ya que la responsabilidad ex culpa es una exigencia de justicia (cfr. can. 128), por haberse omitido la debida diligencia. 
tre formando parte de un proceso ante la Rota, también las normas relativas a la composición interna de la Rota tienen en realidad una repercusión sobre todos los fieles, por lo que es claro que estas Normas constituyen una ley universal.

No es posible aquí realizar una descripción, ni siquiera sumaria, de todas las disposiciones contenidas en estas Normas. A los efectos que interesan al presente estudio, basta señalar que al Decano de la Rota se le atribuyen no pocas facultades en su papel de dirección del tribunal, si bien no se cambia el principio según el cual es un juez más del Tribunal.

Después de las citadas Normas, Benedicto XVI, mediante el Motu Proprio Quaerit semper, de 30 de agosto de 2011, dispuso que en la Rota («apud hoc Tribunal») se constituyese el Officium encargado de conocer las causas sobre el matrimonio rato y no consumado (juzgar sobre el hecho y sobre la existencia de la iusta causa dispensationis) y sobre la validez de la ordenación sacer$\operatorname{dotal}^{32}$. Se ha afirmado que tal Oficina es de naturaleza administrativa y que sus competencias administrativas no alteran la fisonomía del Tribunal judicial de la Rota Romana ${ }^{33}$. Dicho de otro modo, se trata de una Oficina añadida a la Rota, que no modifica la composición del Tribunal ni su función judicial.

Otra decisión de Benedicto XVI respecto a la Rota Romana presenta mayor interés, al menos para el estudioso. Se trata del Rescripto ex audientia Ss.mi, de 11 de febrero de 2013, es decir, del mismo día en que el Papa declaró su voluntad de renunciar al pontificado, en el que, según la terminología del rescripto, se concedían «facultades especiales» a la Rota, pero se trataba en su mayor parte de disposiciones normativas generales universales, o sea, que afectaban, no sólo al funcionamiento interno de un organismo (en este caso, al Tribunal de la Rota Romana), sino a cualquier fiel que instaure una relación jurídica con la Rota, dadas sólo para un trienio ${ }^{34}$. A parte las cuestiones formales, las concretas disposiciones suscitaron críticas entre la doctrina ${ }^{35}$.

\footnotetext{
AAS 103 (2011) 570.

33 Cfr. A. STANKIEWICZ, Un'innovazione storica, en L'Osservatore Romano, 28 settembre 2011, 7, y J. LLOBELL, Il m.p. «Quaerit semper» sulla dispensa dal matrimonio non consumato e le cause di nullità della sacra ordinazione, en Stato, Chiese e pluralismo confessionale, Rivista telematica, 24/2012 (www.statochiese.it, 9 luglio 2012).

${ }^{34}$ El Rescripto no ha sido promulgado en AAS. Puede consultarse, por ejemplo, en Norme procedurali canoniche commentate, cit., 216.

35 Así se reconoce en una editorial del Studio Rotale, aunque se citan dos precedentes de concesión de facultades extraordinarias (cfr. Le facoltà speciali del Decano della Rota Romana. Una lettura storica, Quaderni dello Studio Rotale 22 [2015] 39 y 40, y los textos de las concesiones de facultades recogidos en las páginas siguientes).
} 
Las decisiones del Rescripto eran las siguientes. Se anulaba la necesidad de la segunda conforme para las sentencias dictadas por la Rota que declaraban la nulidad del matrimonio, se impedía la posibilidad de presentar ante este tribunal la nova causae propositio después de que una de las partes hubiese contraído matrimonio canónico y se negaba la apelación contra las decisiones rotales en materia de nulidad de sentencias o decretos. Como se ve, se trata de normas generales que afectan a la posición jurídica de los fieles; la previsión de vigencia de tres años plantea el problema de la igualdad ante la ley en cuestiones tan importantes como éstas, relativas al estado de las personas. Además de estas normas, el Rescripto concedía al Decano la facultad extraordinaria de dispensar de las Normas de la Rota en materia procesal, lo que causa una natural aprensión, pues la concesión a una autoridad judicial de un poder discrecional capaz de cambiar el desarrollo previsto del proceso pone en juego el derecho al justo proceso, por falta de seguridad jurídica y porque el incumplimiento de una norma procesal provoca habitualmente una desventaja jurídica para una de las partes. Por último, se daba una norma de carácter más bien exhortativo, acerca de la obligación de los abogados rotales de cuidar que las causas no durasen más de un año y medio en el Tribunal apostólico.

Con la reforma del proceso de nulidad matrimonial llevada a cabo por el Papa Francisco mediante el Motu Proprio Mitis iudex, de 15 de agosto de 2015 (y del paralelo Motu Proprio Mitis et Misericors Iesus, de la misma fecha, para las Iglesias orientales) ${ }^{36}$, la Rota Romana permanece como tribunal de apelación a la Santa Sede, pero esta norma ha afectado indirectamente a la Rota, hasta el punto de que en el mismo Motu Proprio se anuncia una nueva ley propia de este Tribunal. Esa nueva ley no ha sido promulgada todavía, pero han sido emanadas algunas disposiciones que configuran las competencias de la Rota Romana.

Así, con rescripto del Papa, de 7 de diciembre de 2015, el Romano Pontífice, además de declarar abrogada cualquier norma contraria hasta entonces vigente, independientemente de su rango, ha confirmado sin límite de tiempo las disposiciones de Benedicto XVI de 2013 sobre la inapelabilidad de las decisiones rotales sobre la nulidad de sentencias o decretos, sobre la improponibilidad de la nova causae propositio cuando una de las partes ha contraído ma-

${ }^{36}$ Cfr. AAS 107 (2015) 946-970. Los dos Motu Proprio disponían que habían de entrar en vigor el 8 de diciembre de 2015, pero el fascículo del AAS fue publicado de hecho después de esa fecha. 
trimonio canónico (añadiendo que a no ser que conste la injusticia de la decisión) y sobre la facultad del Decano de dispensar de las normas rotales en materia procesal ${ }^{37}$. Además, el Papa ha establecido mediante esta norma tres disposiciones más: que ante la Rota el dubium sea fijado mediante la fórmula «an constet de matrimonii nullitate, in casu», es decir, sin determinar el capítulo de nulidad; que los tribunales territoriales tengan competencia sobre las causas iurium anejas a las causas matrimoniales sometidas a juicio en la Rota en grado de apelación, y que la Rota Romana juzgue según la gratuidad evangélica. Cada una de estas nuevas normas merecen ser estudiadas con profundidad, pero esa tarea excede de los límites de este trabajo ${ }^{38}$. Aquí interesa, en cambio, llamar la atención sobre un inciso presente en el proemio a las normas, cuando, al recordar la función de la Rota, prevista en la PB, de tutelar la unidad de la jurisprudencia, se añade que se reconoce a la Rota la función de subsidio a la formación permanente de los operadores pastorales en los tribunales de las Iglesias locales.

Lo que era un inciso de la introducción a la parte dispositiva ha tenido un desarrollo normativo. En un Rescripto ex audientia Ss.mi, fechado el 22 de enero de 2016, el Papa, además de instituir un Fondo para el gratuito patrocinio ante la Rota Romana, después de haber confirmado la misión del Estudio Rotal, establece que el Decano de la Rota, oído el parecer del Colegio de Auditores en la sesión, ya celebrada de 16 de diciembre de 2015, instituya un diploma minore de formación jurídica-pastoral para eclesiásticos y laicos que no poseen los títulos de licencia o doctorado, que se conseguirá mediante cursos

37 Cfr. FRANCISCO, Rescriptum circa novam legem efficiendam atque servandam de processu matrimonia$l i$, del 7 de diciembre de 2015, AAS 108 (2016) 5 y 6. No se afirma que sea un rescripto $e x$ audientia Ss.mi, sino que es un documento firmado por el mismo Papa (en la primera publicación, en L'Osservatore Romano de 12 de diciembre de 2015, 8, se decía «ex audientia Ss.mi»). Observando la norma tal y como ha sido promulgada en AAS ha de concluirse que no estamos ante un rescripto, entendido como un acto administrativo singular del que tratan los cann. 59 y siguientes, sino ante una ley universal con un nomen iuris diverso al de su contenido, quizás para hacer referencia a una petición recibida, como sucede con los rescriptos. Tratándose de una ley de alcance universal, surge la cuestión de su promulgación en lengua vernácula.

${ }^{38}$ Por ejemplo, la disposición acerca de la gratuidad evangélica que determina tal gratuidad mediante el patrocinio ex officio («la Rota Romana giudichi le cause secondo la gratuità evangelica, cioè con patrocinio ex officio») no puede interpretarse en el sentido de negar la libre elección del abogado de confianza porque sería contrario al derecho de defensa. Cfr. en este sentido la carta del Secretario de Estado al Decano de la Rota, de 18 de febrero de 2017 a la que se hace referencia en numerosos blogs de internet (cfr., por ejemplo, http://www.lastampa.it/2017/03/ 09/vaticaninsider/ita/vaticano/il-papa-risolve-il-pasticciaccio-della-rota-hRRESL9SfipGQN wcjnDCaM/pagina.html) (consultado el 25 de octubre de 2017). 
desarrollados en la Urbe o fuera o incluso por vía telemática ${ }^{39}$. El citado Rescripto determina la disposición decretando que una Comisión de Auditores, que ha de crear y presidir el Decano de la Rota prepare el programa de tal curso, definiendo los créditos que ha de tener y la modalidad de los exámenes. De esta manera, la Rota Romana, además de la función judicial y de la Oficina para las causas de dispensa del matrimonio rato y no consumado y de nulidad de la ordenación, ha asumido una función docente, de formación del personal que actúa en los tribunales locales.

En este contexto ha sido difundido un Sussidio applicativo del Mitis Iudex, primero en italiano y después en otras lenguas, en el que el Tribunal de la Rota Romana aparece como autor. En la carta de acompañamiento enviada por el Decano de la Rota a los obispos, fechada el 26 de enero de 2016, se afirma que el Subsidio ha sido elaborado per Superiore disposizione ${ }^{40}$. Este documento ha sido visto como una manifestación de la función de impartir una formación permanente de quienes trabajan en los tribunales eclesiásticos locales ${ }^{41}$. Aunque se reconoce su diferencia con la Dignitas connubii por su finalidad y espíritu ${ }^{42}$, han surgido entre los autores algunas dudas acerca de su naturaleza jurídica.

Por mi parte no veo ninguna dificultad en negar con certeza cualquier valor normativo a este documento, por la sencilla razón de que su autor, al ser un tribunal judicial, carece de potestad normativa, tanto legislativa como administrativa, y no consta en ningún momento que haya recibido una delegación normativa ${ }^{43}$. La referencia a la Superiore disposizione no añade nada: mientras no conste otra cosa, la disposición superior consiste en que se redacte un subsidio, que es algo distinto a una norma, como se nota en el estilo mismo del documento. No obstante, la cuestión sobre su naturaleza jurídica surge porque en este texto, como es casi inevitable, hay interpretaciones, explicaciones y aplicaciones que pueden ir más allá de la norma que comenta. Me parece que en todo aquello que no se ciña a la ley promulgada, las orientaciones del Subsidio no

39 Rescriptum ex Audientia SS.mi, de 22 de enero de 2016, Quaderni dello Studio Rotale 23 (2016) 4748, firmado por el mismo Decano de la Rota. En el Rescripto se establece que se publique en AAS. Hasta ahora (cuando el último número de AAS es el de diciembre de 2016) no ha sido publicado.

${ }^{40}$ La carta puede consultarse en Quaderni dello Studio Rotale 23 (2016) 169.

${ }^{41}$ Cfr. M. DEL Pozzo, Il processo matrimoniale più breve davanti al vescovo, Edusc, Roma 2016, 38.

${ }^{42}$ Cfr. ibid., 68.

${ }^{43} \mathrm{Y}$ desde luego no es deseable que llegue a tener también potestad normativa. J. FERRER OrTiZ, Valoración de las circunstancias que pueden dar lugar al proceso abreviado, Ius Canonicum 56 (2016) 189, ha advertido acertadamente sobre el «peligro de dar cabida dentro de la Iglesia a un cierto activismo judicial, donde el juez asume la función del legislador o de intérprete auténtico de la ley universal». 
pueden pasar de ser unas opiniones, más o menos autorizadas, pero para nada vinculantes. Otro tema es que de hecho pasen a generar costumbre ${ }^{44}$.

\section{REFLEXIONES CONCLUSIVAS}

$\mathrm{Al}$ repasar los acontecimientos habidos después de la promulgación de la Constitución Apostólica PB sobre los tres tribunales apostólicos estudiados, llama la atención el volumen tan notable de la actividad que ha existido en torno a ellos, sin duda mayor de la que cualquiera podría haber imaginado en los años ochenta, cuando había quien pensaba que la normativa canónica ya había quedado fijada después del Vaticano II y que la praxis jurídica era algo marginal y casi residual en la vida de la Iglesia. Los hechos han desmentido tal suposición y han demostrado que las relaciones de justicia dentro de la Iglesia existen y que la naturaleza caída del hombre, aunque redimido, provoca problemas jurídicos que se han de resolver. Teniendo esto en cuenta, y que no es exagerado afirmar que el derecho vive en el proceso, no es de extrañar que los tribunales y los procesos reclamen revisiones normativas.

Los desarrollos normativos relativos a los tribunales apostólicos sugieren más de una reflexión, que pueden traducirse en propuestas de iure condendo, especialmente en estos momentos en los que se desea proceder a una reforma de la Curia Romana. De esta manera, el canonista puede cumplir una de sus funciones, es decir, la de contribuir desde el punto de vista de la ciencia del derecho a mejorar las leyes.

\subsection{La tutela de los derechos en los tribunales apostólicos}

El jurista no puede quedar indiferente al comprobar en esta reseña de los cambios y desarrollos habidos en los tribunales apostólicos las anomalías formales con las que se han realizado las reformas normativas, precisamente en

${ }^{44}$ En la doctrina, se ha negado su valor normativo (cfr., por ejemplo, F. HEREDIA EsTEBAN, El proceso más breve ante el Obispo, Anuario de derecho canónico 5 [2016] 99) o se ha afirmado que su «naturaleza jurídica no es fácil de precisar» (G. NúÑEZ, El proceso brevior: exigencias y estructura, Ius Canonicum 56 [2016] 136), pero de hecho los mismos autores citan y dan por buenas las afirmaciones del Subsidio, otorgándole de hecho un valor cercano al normativo. De modo más neto y argumentado niega el valor normativo de este texto G. BONI, La riforma del processo canonico di nullità matrimoniale: il complicarsi progressivo del quadro delle fonti normative (parte seconda), Stato, Chiese e pluralismo confessionale, 2018, n. 5, 83-98. 
una materia en la que está en juego la defensa de los derechos de los fieles. Aplicación de leyes no promulgadas (y, por tanto, en rigor, inexistentes), incerteza sobre la capacidad normativa del autor de las normas o incluso sobre quién es el autor, tipo formal de la norma dudoso o denominado con un nombre distinto al legal, anulación de la vacatio legis y otras rarezas canónicas que se han ido viendo en estas páginas denotan una actitud antes estas cuestiones que no toma en consideración las repercusiones que, para la justicia sustancial, tienen estos requisitos formales. La claridad de la norma da certeza ante ella, lo que constituye un derecho de los sujetos pasivos y un instrumento que obstaculiza el abuso de poder. Urge, por tanto, respetar la legalidad en la producción normativa, aunque es posible que convenga para ello reformar el can. 8 relativo al modo de promulgación de las leyes.

A la hora de examinar las intervenciones pontificias de los últimos decenios en el campo penal, surgen numerosas consideraciones. Algunas son relativas al derecho penal mismo, que aquí sólo enuncio. La atención legislativa y judicial se han concentrado en los delitos de pederastia cometidos por clérigos para hacer frente a la avalancha de escándalos gravísimos. Esta situación de emergencia ha podido hacer olvidar el daño que pueden producir al pueblo cristiano otros comportamientos ilícitos, como, por ejemplo, aquellos contrarios a la fe, que, en cambio, quedan de hecho impunes, de manera que la selección de la actividad sancionadora puede provocar en el Pueblo de Dios una concepción distorsionada de los bienes eclesiales. Por lo demás, es común entre los canonistas la preocupación por algunas medidas extraordinarias y de urgencia que, para obtener la reparación de un daño, ponen en peligro otros bienes jurídicos, como es el caso de la facultad otorgada a la autoridad de prescindir del derecho a no ser castigado, adquirido mediante la prescripción del delito.

Desde el punto de vista organizativo, surge en primer lugar la cuestión de la división de funciones. A pesar de no ser una exigencia absoluta de justicia, la división de funciones constituye un instrumento que ayuda al ejercicio justo del gobierno y como tal fue puesto como principio que había de estar en la base del Código de 1983. Teniendo en cuenta que se había identificado este principio como un buen medio para garantizar la justicia en el ejercicio de la potestad, y que es derecho de los fieles que haya un buen gobierno, llama la atención que haya sido abandonado precisamente en la materia penal, donde están en juego los bienes jurídicos más relevantes para las personas. Ya la PB atribuía a la CDF, organismo de naturaleza administrativa, la función de juzgar los delitos más graves, dando con esto un paso atrás respecto al Código; el 
desarrollo posterior ha reforzado esta tendencia. Además de la acumulación de funciones en un mismo organismo, se da una confusión de funciones en el mismo procedimiento; la vía administrativa para juzgar delitos e imponer penas, concebida en el Código como una posibilidad excepcional, se ha extendido hasta el punto de ser en la práctica el procedimiento más común en la imposición de las penas más graves, a pesar de que se trata de una vía que no garantiza la imparcialidad del juez ni el derecho de defensa del acusado.

Tratando de la función judicial de la Santa Sede, sorprende el hecho mismo de la reserva de los delitos más graves, a la luz de la teología de la potestad del Obispo en su diócesis: precisamente porque son delitos que revisten especial gravedad, el Obispo del lugar donde se ha producido el daño debería intervenir con su potestad, mientras que la Santa Sede debería quedar libre de una responsabilidad de la que difícilmente puede hacerse cargo. La trascendencia universal que pudiera tener un determinado delito puede ser reparada en la sede donde se cometió. Además, en materia de juicio penal resulta evidente la conveniencia de la inmediatez. En resumen, desde una perspectiva de iure condendo parece muy conveniente una desconcentración de esta materia, especialmente en un momento en el que el mismo Romano Pontífice ha manifestado el deseo de proceder a una saludable "descentralización" ${ }^{45}$, quedando a salvo, como es lógico, la responsabilidad de la Santa Sede de vigilar para que se realice efectivamente la justicia en las distintas partes de la Iglesia y la posibilidad de apelar al Papa, a través del tribunal competente, tanto por parte de la acusación como del imputado. Por lo demás, la responsabilidad de los tribunales locales en materia de nulidad matrimonial, recientemente reforzada, impide que pueda alegarse la dificultad técnica de juzgar un proceso penal, de por sí menos arduo que el juicio sobre la validez del vínculo matrimonial ${ }^{46}$.

\subsection{El papel de la jurisprudencia}

Por último, merece una consideración aparte el tema del papel de la jurisprudencia y la función atribuida recientemente a la Rota Romana de con-

45 Cfr. Francisco, Exhortación Apostólica Evangelii Gaudium, de 24 de noviembre de 2013, n. 16 (AAS 105 [2013] 1027).

46 En el caso del proceso penal parece particularmente oportuno que sea desconcentrado en favor de jueces vicarios, ya que la titularidad de la acción penal corresponde al Obispo diocesano (can. 1721). 
tribuir a la formación permanente de los operadores pastorales en los tribunales de las Iglesias locales.

Respecto a la jurisprudencia, pienso que conviene aclarar una confusión que parece darse no pocas veces entre la doctrina científica y la jurisprudencial, tanto en lo que se refiere a los respectivos contenidos como a su distinto valor. La doctrina científica trata los temas de modo abstracto, intentado encontrar las causas de las cuestiones jurídicas, y lo debe hacer con exhaustividad de argumentos y de fuentes documentales y doctrinales. El valor de un estudio doctrinal radica en su fuerza argumentativa, en la objetividad del tema tratado abstractamente y, en definitiva, en su autoridad científica, avalada por el uso estricto del método científico. Si una determinada opinión científica se convierte en constante y común adquiere lógicamente una autoridad especial, que influye en el legislador y en el juez.

El modo de proceder de la doctrina jurisprudencial, en cambio, es distinto porque su finalidad es otra. La doctrina jurisprudencial nace del razonamiento para alcanzar la justicia en el caso concreto. No es, por tanto, abstracta, sino que apunta a la solución de un problema concreto, aunque pueda sentar un principio general por inducción o por recepción de la doctrina científica. Habida cuenta de su finalidad, no necesita la exhaustividad del tratado científico, sino que es suficiente que exponga la ratio decisionis.

El valor de la doctrina jurisprudencial no se basa en los criterios de cientificidad sino en la fuerza del razonamiento de una solución concreta justa, que ha causado una decisión obligatoria, de suerte que al convencimiento del razonamiento se añade lo que es específico de la jurisprudencia, o sea, el que se trata de un precedente. En el ámbito del derecho canónico ya Inocencio III observó que «in similibus casibus ceteri teneantur similiter iudicare ${ }^{47}$. En efecto, constituye un derecho del fiel ser juzgado similiter in similibus, pues ha de darse igualdad ante la justicia. Por tanto, para garantizar la recta administración de la justicia, resulta necesario conocer todos los precedentes jurisprudenciales, los que marcan una trayectoria constante, los que representan un caso único y los que son excepcionales, para poder defender los derechos y poder aplicar, cuando sea el caso, la analogía, según el célebre brocardo ubi eadem

${ }^{47} \mathrm{X}$ 2.27.19. Para algunos datos sobre el valor de la jurisprudencia en la historia del derecho canónico, cfr., por ejemplo, Z. VAralta, De iurisprudentiae conceptu, Periodica 62 (1973) 44-49, y G. Fransen, La valeur de la jurisprudence en droit canonique, en La norma en el Derecho Canónico. Actas del III Congreso Internacional de Derecho Canónico. Pamplona 10-15 de octubre de 1976, vol. I, Eunsa, Pamplona 1976, 197-212. 
ratio est, ibi eadem iuris dispositio esse debet. La conclusión lógica de estas consideraciones es que resulta necesaria la publicación de la jurisprudencia porque no se trata -vale la pena insistir- en una doctrina que goce de mayor autoridad porque proviene de una determinada instancia más prestigiosa que la de un cierto autor o la de una determinada escuela, sino porque es un precedente de la administración de justicia.

Ahora bien, para que la jurisprudencia tenga verdaderamente el valor que le corresponde es imprescindible que su publicación sea completa (respetando siempre la debida reserva y fama de las personas). La praxis tradicional de la Rota Romana consiste en publicar sólo una selección de sus decisiones. Respecto a la Signatura Apostólica, después de años sin poder conocer sus decisiones, la nueva Lex propria ha establecido en su art. $11, \$ 4$ que corresponde al Prefecto elegir las sentencias que han de ser publicadas. Actualmente este Tribunal ofrece a algunas revistas de Derecho Canónico la posibilidad de publicar algunas sentencias, estableciendo en la práctica el requisito de poder revisar previamente, no sólo la traducción, sino también el comentario con el que se publique la decisión. En fin, como es sabido, se carece totalmente de la publicación de la jurisprudencia en materia penal.

La selección de la jurisprudencia tiene razón de ser si su valor y finalidad fuesen los mismos que los de la doctrina científica. Es justo reconocer que la publicación selectiva de la jurisprudencia ayuda al desarrollo de la doctrina y puede orientar a la jurisprudencia de los tribunales inferiores, así como la publicación parcial de las decisiones de la Signatura a través de las revistas científicas ayuda al progreso del derecho administrativo y procesal. Ahora bien, este resultado es el mismo que se puede conseguir a través de los trabajos científicos. Permanece en todo caso la objeción que la publicación parcial de los precedentes judiciales no satisface las exigencias jurídicas del derecho fundamental de defensa. La praxis de seleccionar las sentencias (e incluso de corregirlas materialmente antes de su publicación), y, en el caso de la Signatura, de seleccionar también las revistas, supone, en mi opinión, confundir el papel de un tribunal con el de un autor privado. Por lo demás, pienso que la supeditación de la entrega de un texto al control previo de su comentario es posible cuando el autor del texto es un privado, mientras que cuando el autor es una autoridad en el ejercicio de su función pública surge el problema del respeto debido al derecho fundamental a la libertad de investigación y expresión, reconocido en el can. 218.

La falta de publicidad de la jurisprudencia y su ausencia en muchos campos del derecho han fomentado el legalismo, hasta el punto de que se ha dado 
la paradoja histórica de que, después de los temores para adoptar la codificación, el derecho canónico se ha hecho en su praxis y reflexión científica el derecho más "codicialista".

Ya ha quedado dicho que el art. 126 de la PB atribuye a la Rota Romana la función de proveer «a la unidad de la jurisprudencia y, a través de sus sentencias, sirve de ayuda a los tribunales de grado inferior». Sobre la unidad de la jurisprudencia se ha discutido en la doctrina ${ }^{48}$. Por un lado, es deseable esa unidad por el principio de igualdad ante la justicia. Por otro, es necesario respetar la libertad y conciencia del juez. La jurisprudencia inferior no carece de valor y puede también iluminar la de la Rota, pero más bien al modo con que lo hace la doctrina científica. En cambio, el influjo de la jurisprudencia de la Rota sobre los demás tribunales es de otro orden porque, al tratarse del tribunal de apelación, puede contribuir a la unidad de la jurisprudencia. Cabe suponer que la eliminación del requisito de la doble conforme supondrá una disminución notable de esta función de la Rota Romana.

\subsection{La función formativa en el ámbito del derecho canónico}

En este contexto de la misión de la Rota de contribuir a la unidad de la jurisprudencia se ha añadido recientemente la función de ayudar a la formación permanente de quienes operan en los tribunales. No se trata de una competencia más, afín a la función natural del organismo, sino que es ciertamente una función de naturaleza totalmente distinta a la del papel propio de un tribunal ${ }^{49}$.

La ampliación de funciones de la Rota, no ya de gobierno, sino de formación, ha causado algunas reacciones negativas en la doctrina. Se ha hecho notar que la formación permanente presupone la inicial, que consiste concretamente en la licencia y el doctorado en derecho canónico ${ }^{50}$, y se ha puesto de

${ }^{48}$ Sobre el tema me remito a E. BAURA, Riflessioni sul valore canonico della giurisprudenza, en J. KoWAL - J. LlOBELL (eds.), «Iustitia et iudicium». Studi di diritto matrimoniale e processuale canonico in onore di Antoni Stankiewicz, vol. III, Libreria Editrice Vaticana, Città del Vaticano 2010, 13871406 y a la bibliografía ahí citada.

49 Es significativo, por ejemplo, que en un estudio sobre la Rota Romana no se sienta la necesidad de tratar del papel formativo de este tribunal (cfr. I. SASSANELLI, Il Tribunale della Rota Romana nell'odierno sistema processuale canonico, Apollinaris 88 [2015] 659-685).

50 Cfr. M. Arroba Conde, L'esperienza sinodale e la riforma del processo matrimoniale, en P. PALUMBо (ed.), Matrimonio e processo per un nuovo umanesimo. Il M.P. Mitis iudex Dominus Iesus di Papa Francesco, Giappichelli, Torino 2016, 139. 
manifiesto que esta decisión puede crear un agravio comparativo entre quienes son doctores, y quizás han hecho también los estudios de abogado rotal, y aquellos que poseen sólo el diploma minore, con el riesgo de que una equiparación de este tipo lleve a abandonar el estudio del derecho canónico a nivel universitario, lo que provocaría un empobrecimiento para la administración de justicia en toda la Iglesia ${ }^{51}$.

En efecto, la atribución de una función formativa a la Rota plantea algunos problemas, en primer lugar, algunos de carácter práctico. Así, habría que ver cómo puede el tribunal organizar esa formación sin desatender su trabajo propio, ya que se requiere una organización material y una dedicación temporal que puede resultar incompatible con los quehaceres de los jueces, además de que no se puede exigir siempre al juez, aunque sea un gran conocedor de la materia, la profesionalidad de un formador, pues es distinta de la que se requiere a un juez. Es verdad que la Rota cuenta desde antiguo con el Estudio Rotal, pero se trata de un centro de formación especializada, sito en la misma sede del tribunal, que se dirige a quienes han obtenido ya el doctorado en derecho canónico para prepararlos en el ejercicio de la profesión de abogado en el mismo tribunal. Ahora se trata de la formación permanente -y, según los últimos desarrollos, de la primera formación- de quienes actúan en los tribunales periféricos, lo que resulta muy distinto y plantea los problemas prácticos a los que he aludido. Además, esta nueva función puede entrar en contradicción con la función reconocida por la Santa Sede a los entes académicos que de ella dependen. Teniendo en cuenta estos problemas, comparto la idea de que la Rota debe contribuir a la formación a través de sus sentencias, lo que exige que sean escritas con calidad y publicadas tempestivamente ${ }^{52}$; la publicación de la jurisprudencia contribuye a la unidad porque ayuda al mismo tiempo a la formación jurídica de los jueces a través de la función propia del tribunal apostólico de apelación.

Al margen de estos problemas prácticos, surge la cuestión de la formación canónica en sí. Será más o menos perentoria la necesidad de contar con personas dotadas de una pericia técnica para desarrollar determinadas funciones en los procesos de nulidad matrimonial. Pero pienso que lo que resulta extremadamente necesario es contar con canonistas bien formados en los tribunales y en otras instancias de la Iglesia. No se trata sólo de que posean un título

${ }_{51}$ Cfr. G. BonI, La riforma del processo canonico di nullità matrimoniale..., cit., 94-97

${ }^{52}$ Cfr. en este sentido M. ARroba Conde, L'esperienza sinodale..., cit., 139 y 140. 
académico, sino de personas con cultura jurídica, con conocimiento profundo de las exigencias de justicia que se dan dentro del Pueblo de Dios.

Una sociedad en la que no hay sensibilidad por lo jurídico es una comunidad retrasada. La grandeza de una civilización no es debida tanto a sus logros técnicos, sino a la sabiduría con la que es capaz de gobernarse. Para lograr la paz social, que es fruto de la justicia, es necesario la labor de verdaderos juristas, no de personas que conozcan el mecanismo práctico del aparato administrativo o judicial, sino de quienes sean capaces de descubrir los derechos e identificar sus límites, para proteger el respeto debido a las personas y el ejercicio justo del poder social.

También la Iglesia necesita no sólo el derecho ${ }^{53}$, sino una cultura jurídica, difundida en todo el Pueblo de Dios, pero de modo especial en quienes tienen responsabilidades públicas. El antijuridicismo práctico que se ha introducido en amplios ámbitos de la Iglesia a partir de los años inmediatamente posteriores al Vaticano II ha dejado una profunda huella. Las anomalías en los actos de gobierno relativos a los tribunales apostólicos que se han visto en estas páginas no son simples deficiencias técnicas; superarlas ayudaría a la recta administración de la justicia en materias de grande importancia para la vida de los fieles. El problema, por tanto, no está en preparar técnicamente un buen número de peritos en cuestiones marginales del proceso matrimonial. Más aún, la habilitación técnica sin una adecuada base jurídica puede ser deletérea para la aplicación de la justicia. Se trata, en cambio, de formar verdaderos juristas para conseguir difundir en la Iglesia una cultura y sensibilidad jurídicas que lleven al respeto de los derechos de los fieles. La formación jurídica que se necesita impartir no consiste en la mera transmisión de los datos legislativos, sino en una formación profunda, a nivel universitario, capaz de comprender las exigencias de justicia presentes en la Iglesia.

53 Cfr. Benedicto XVI, Carta a los seminaristas, de 18 de octubre de 2010, n. 5 en https://w2.vatican.va/content/benedict-xvi/es/letters/2010/documents/hf_ben-xvi_let_20101018_seminaristi.html (consultado el 25 de octubre de 2017). 


\section{Bibliografía}

ARroba Conde, M., L'esperienza sinodale e la riforma del processo matrimoniale, en P. Palumbo (ed.), Matrimonio e processo per un nuovo umanesimo. Il M.P. Mitis iudex Dominus Iesus di Papa Francesco, Giappichelli, Torino 2016, 129-148.

Astigueta, D. G., Il nuovo Collegio all'interno della Congregazione per la dottrina della fede e il suo regolamento, Periodica 105 (2016) 335-363.

BAURA, E., Analisi del sistema canonico di giustizia amministrativa, en E. BAURA - J. CANOSA (eds.), La giustizia nell'attività amministrativa della Chiesa Il contenzioso amministrativo, Giuffrè, Milano 2006, 2-58.

-, Riflessioni sul valore canonico della giurisprudenza, en J. KOWAL - J. LlOBELL (eds.), «Iustitia et iudicium». Studi di diritto matrimoniale e processuale canonico in onore di Antoni Stankiewicz, vol. III, Libreria Editrice Vaticana, Città del Vaticano 2010, 1387-1406.

BONI, G., La riforma del processo canonico di nullità matrimoniale: il complicarsi progressivo del quadro delle fonti normative (parte seconda), Stato, Chiese e pluralismo confessionale, 2018, n. 5, 83-98.

Bonnet, P. A. - Gullo, C. (eds.), Le «Normae» del Tribunale della Rota romana, Libreria Editrice Vaticana, Città del Vaticano 1997.

—, La lex propria del S.T. della Segnatura Apostolica, Libreria Editrice Vaticana, Città del Vaticano 2010.

Burke, R., La Segnatura Apostolica: gli organi individuali, en P. A. BONNET C. Gullo (eds.), La lex propria del S.T. della Segnatura Apostolica, Libreria Editrice Vaticana, Città del Vaticano 2010, 79-81.

—, Presentazione, en M. Del Pozzo - J. Llobell - J. MiÑAmbres, Norme procedurali canoniche commentate, Coletti a San Pietro, Roma 2013, 29-34.

Canosa, J., Gli organi collegiali previsti dalla «Lex propria» della Segnatura Apostolica, en P. A. BonNET - C. Gullo (eds.), La lex propria del S.T. della Segnatura Apostolica, Libreria Editrice Vaticana, Città del Vaticano 2010, 107-116.

CITO, D., Las nuevas normas sobre los «delicta graviora», Ius Canonicum 50 (2010) 643-658.

-, Congregazione per la Dottrina della Fede. Normae «de gravioribus delictis», en M. DEL PoZZO - J. Llobell - J. MiÑAMBRES, Norme procedurali canoniche commentate, Coletti a San Pietro, Roma 2013, 628-630. 
Daneels, F., La nuova Lex propria del Supremo Tribunale della Segnatura Apostolica, Communicationes 40 (2008) 336-341.

D'Auria, A. - PAPAle, C. (eds.), I delitti riservati alla Congregazione per la Dottrina della Fede, Urbaniana University Press, Città del Vaticano 2014.

Del Pozzo, M., Il processo matrimoniale più breve davanti al vescovo, Edusc, Roma 2016.

Del Re, N., La Curia Romana. Lineamenti storico-giuridici, Libreria Editrice Vaticana, Città del Vaticano 1998.

DE PaOlis, V., Norme de gravioribus delictis riservati alla Congregazione per la dottrina della fede, Periodica 91 (2002) 273-312.

FRANSEN, G., La valeur de la jurisprudence en droit canonique, en La norma en el Derecho Canónico. Actas del III Congreso Internacional de Derecho Canónico. Pamplona 10-15 de octubre de 1976, vol. I, Eunsa, Pamplona 1976, $197-$ 212.

Green, T. J., Sacramentorum sanctitatis tutela. Reflections on the Revised May 2010 Norms on More Serious Delicts, The Jurist 71 (2011) 120-158.

GrocholeWski, Z., La «Sectio Altera» della Segnatura Apostolica con particolare riferimento alla procedura in essa seguita, Apollinaris 54 (1981) 65-110.

Heredia Esteban, F., El proceso más breve ante el Obispo, Anuario de derecho canónico 5 (2016) 97-122.

LLOBELL, J., Il «petitum» e la «causa petendi» nel contenzioso-amministrativo canonico. Profili sostanziali ricostruttivi alla luce della cost. ap. «Pastor Bonus», Ius Ecclesiae 3 (1991) 119-150.

-, Sulla promulgazione delle norme processuali proprie della Congregazione per la dottrina della fede in materia penale, Ius Ecclesiae 9 (1997) 289-301.

-, Le norme della Rota romana in rapporto alla vigente legislazione canonica: la «matrimonializzazione» del processo; la tutela dell'«ecosistema processuale»; il principio di legalità nell'esercizio della potestà legislativa, en P. A. BONNET C. Gullo (eds.), Le «Normae» del Tribunale della Rota romana, Libreria Editrice Vaticana, Città del Vaticano 1997, 47-92.

—, Il m.p. «Quaerit semper» sulla dispensa dal matrimonio non consumato e le cause di nullità della sacra ordinazione, en Stato, Chiese e pluralismo confessionale. Rivista telematica, 24/2012 (www.statochiese.it, 9 luglio 2012).

-, Processi e procedure penali: sviluppi recenti, en H. FrANCESCHI - M. A. ORTIZ (eds.), «Ius et matrimonium». Temi di diritto matrimoniale e processuale canonico. $V$ Corso di aggiornamento in diritto matrimoniale e processuale canonico. Roma, 16-20 settembre 2013, Edusc, Roma 2015, 75-108. 
Loppacher, S., Processo penale canonico e abuso sessuale su minori. Un'analisi dei recenti sviluppi normativi intorno al «delictum contra sextum cum minore» alla luce degli elementi essenziali di un giusto processo, Pontificia Università della Santa Croce, Roma 2017.

Miras, J. - Canosa, J. - Baura, E., Compendio de derecho administrativo canónico, Eunsa, Pamplona ${ }^{3} 2017$.

Montini, G. P., L'esecuzione delle sentenze della «Sectio Altera» della Segnatura Apostolica. Il significato di una lacuna, en K. LüDICKE - H. MussingHOFF H. SCHWENDENWEIN (eds.), Iustus Iudex. Festgabe für Paul Wesemann zum 75. Geburtstag von seinen Freunden und Schülern, Ludgerus, Essen 1990, 553-571.

—, I ricorsi amministrativi presso il Supremo Tribunale della Segnatura Apostolica, en Gruppo Italiano Docenti Di DiritTo Canonico (ed.), Il diritto nel mistero della Chiesa, vol. IV: Prassi amministrativa e procedure speciali, Lateran University Press, Città del Vaticano 2014, 135-159.

NúÑEZ, G., El proceso brevior: exigencias y estructura, Ius Canonicum 56 (2016) 135-155.

Rodríguez CHacón, R., Promulgación, publicación y entrada en vigor de las leyes en la Iglesia, en J. L. SÁnCheZ-GIRÓN - C. PeÑa GarCía (eds.), El Código de Derecho Canónico de 1983. Balance y perspectivas a los 30 años de su promulgación, Universidad Pontificia Comillas, Madrid 2014, 71-105.

Sassanelli, I., Il Tribunale della Rota Romana nell'odierno sistema processuale canonico, Apollinaris 88 (2015) 659-685.

STANKIEWICZ, A., Un'innovazione storica, en L'Osservatore Romano, 28 settembre 2011, 7 .

Studio Rotale (ed.), Le facoltà speciali del Decano della Rota Romana. Una lettura storica, Quaderni dello Studio Rotale 22 (2015) 39 y 40.

VARalta, Z., De iurisprudentiae conceptu, Periodica 62 (1973) 39-57.

Woestman, W., Ecclesiastical sanctions and the penal process. A commentary on the Code of Canon Law, Otawa 22003.

ZuAnaZZI, I., Praesis ut prosis. La funzione amministrativa nella diakonia della Chiesa, Casa Editrice Jovene, Napoli 2005. 